\title{
Delineation of the Causative Fault of Recent Earthquakes (April-May 2020) in Delhi from Seismological and Morphometric Analysis
}

\author{
Brijesh K. Bansal ${ }^{1,2}$, Kapil Mohan ${ }^{1, *}$, Ahsan Ul Haq ${ }^{3}$, Mithila Verma ${ }^{2}$, \\ S. K. Prajapati ${ }^{1}$ and G. M. Bhat ${ }^{3}$ \\ ${ }^{1}$ National Center for Seismology, Ministry of Earth Sciences, Lodhi Road, New Delhi - 110 003, India \\ ${ }^{2}$ Geoscience/Seismology Division, Ministry of Earth Sciences, Lodhi Road, New Delhi - 110 003, India \\ ${ }^{3}$ Department of Geology, University of Jammu, Jammu - 180 006, India \\ *E-mail: kapil_geo@yahoo.co.in
}

\begin{abstract}
Recently, amid the pandemic of COVID-2019, the north-east Delhi region experienced two small earthquakes in a short span of 1 month; the first occurred on $12^{\text {th }}$ April $2020\left(M_{w} 3.5\right)$ and the other on $10^{\text {th }}$ May $2020\left(M_{w} 3.4\right)$. These events were followed by 4 aftershocks of magnitude $M_{w} \leq 3.0$. We carried out morphotectonic (high stream length-gradient index) and static Coulomb stress failure analyses to delineate the hidden causative fault(s) in the region. In the study, ASTER DEM data of $30 \mathrm{~m}$ resolution and Survey of India (SoI) toposheets on 1:50,000 scales were used for morphotectonic analysis. The analysis depicted a very high stream length-gradient (SL) and fall in elevation in the epicentral area, suggesting the area to be tectonically active with a NE-SW trending fault line. In addition, the nature of static Coulomb failure stress contours for both the main events, $M_{w} 3.5$ and $M_{w} 3.4$, suggests an NNE-SSW trending high Coulomb stress regime. Such a high coulomb stress regime is obvious at the location where a high SL index and fall in elevation were marked, which clearly indicates the presence of NNE-SSW trending a causative fault, named 'Khanpur-Japti fault'.
\end{abstract}

\section{INTRODUCTION}

Delhi region has been affected in the past by interplate seismicity from Himalayan sources, e.g., $\mathrm{M}_{\mathrm{w}} 7.5$ Garhwal-Kumaon Himalaya earthquake in 1803, $M_{w} 6.8$ Uttarkashi earthquake in 1991, $M_{w} 6.6$ Chamoli earthquake in $1999, M_{w} 7.8$ Gorkha earthquake in 2015, and a few moderate earthquakes from the Hindukush region. Further, the region has been experiencing intraplate seismicity. The local seismic sources have produced many significant large earthquakes in the past including, M6.5 Delhi earthquake in 1720, M5.5 Mathura earthquake in 1842, M6.7 Bulandshahar earthquake in 1956, M4.8 Delhi-Gurgaon border 1960, and M5.8 Moradabad earthquake in 1966 (Fig. 1). In addition, the region has witnessed three local seismicity clusters in different areas, viz., Jind, Rohtak, and eastern parts of Delhi during 1960. The seismological characterizations of these local sources were done in the past mostly based on the surface exposure and fault plane solutions.

Recently, during April-May 2020, small earthquakes of $2.0 \leq \mathrm{M}_{\mathrm{w}} \leq 3.5$ occurred in the north-east Delhi border region. Although no damage was reported due to these earthquakes, they created panic among the public during the COVID- 19 coronavirus outbreak. The events occurred along a blind fault with no surface signature. The densely populated Delhi region is not readily amenable to conduct deep geophysical surveys. In such a situation, morphotectonic analysis is found to be a reliable tool to understand the tectonic set-up of the region. Drainage analysis, generally, provides clues to structural features and lithology (Howard, 1967). The morphotectonic study involves the evaluation of stream parameters through the measurements of different stream anomalies (Pirasteh et al., 2007). Since the streams are highly sensitive to any changes in tectonic and climatic conditions of an area, they can be considered as powerful indicators of such activity. In addition to climatic conditions, lithology and geologic structures also have great control over stream processes because they influence the nature of flow, erosion, and sediment transportation.

The deformation and fractures get developed within rock masses when the stress level increases beyond the critical stress. The increase in stress due to earthquakes has been found to trigger aftershocks that usually follow the mainshock in the region of critical failure (Yamashina, 1978; Das and Scholz, 1981). Thus, studying the static

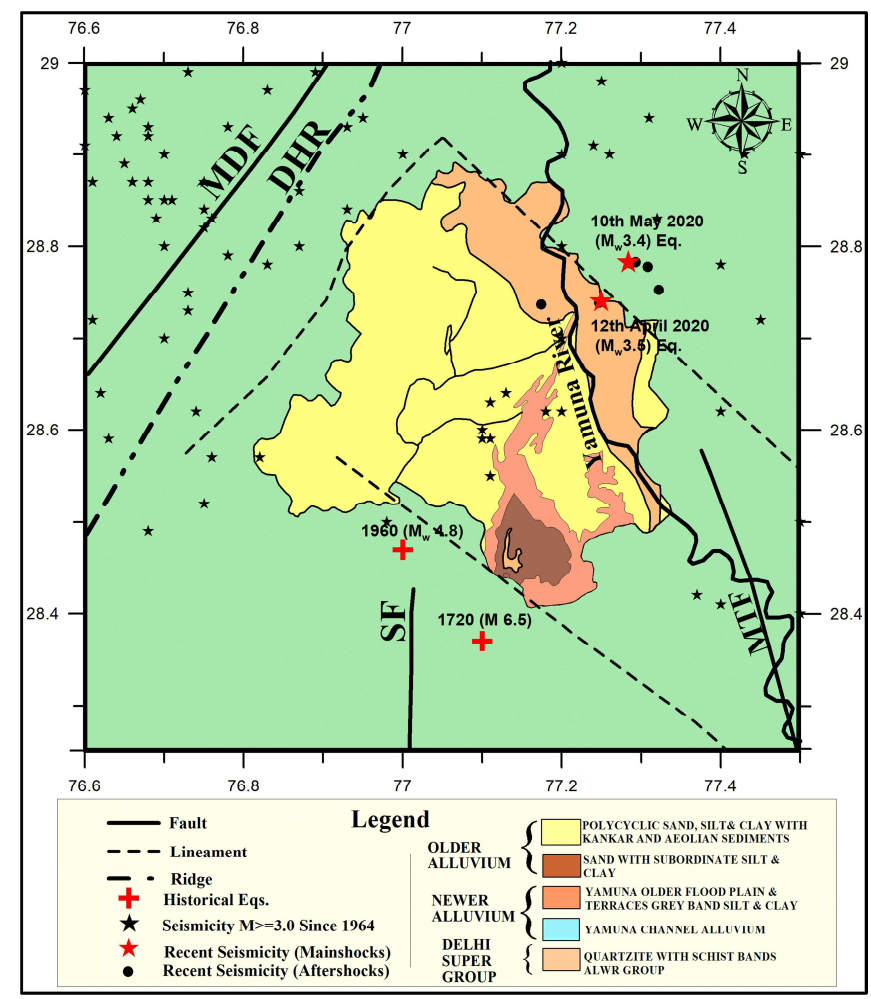

Fig.1. Geological map of the Delhi region (after Kachroo and Bagchi, 1999) overlapped by major faults of the area (after GSI, 2002). MDF: Mahendragarh-Dehradun fault; SF: Sohna Fault; MTF: Mathura Fault and DHR: Delhi-Hardwar Ridge. 
stress changes based on the Coulomb stress transfer model is useful in locating the causative fault and understanding the direction of propagation of the seismic events. In the present study, a joint analysis (morphotectonic and seismological) is undertaken in the NE Delhi region for identifying and characterizing the causative fault of the recent earthquakes.

\section{MORPHOMETRIC ANALYSIS}

Geomorphic indices are important resources to analyze the impact of active tectonics in areas experiencing rapid deformation (Keller and Pinter, 2002) and the analysis of drainage networks is a powerful tool to detect recent tectonic activity and upliftment in the terrain (Clark et al., 2004). The absence of surface impression of fault in the epicentral area of recent earthquakes in NE Delhi leads us to get the idea about subsurface active faulting through analyzing the geomorphic indices of the drainage basin of the Delhi region. Two relevant geomorphic indices have been analyzed in the present study i.e. the River Longitudinal Profiles and the Slope Gradient Index (SL) to identify the tectonically active area in the Delhi region and delineation of hidden causative faults related to two earthquakes of April 12, 2020 $\left(\mathrm{M}_{\mathrm{w}}\right.$ 3.5) and May 10, $2020\left(\mathrm{M}_{\mathrm{w}} 3.4\right)$ in the epicentral zone

The geomorphic indices were calculated using satellite imageries and Geographical Information System (GIS) techniques. The ASTER DEM data of $30 \mathrm{~m}$ resolution (source: bhuvan.nrsc.gov.in) have been used to generate the drainage network of the catchment areas in the Delhi region (Fig. 2). The software ArcGIS 10.3.1, was used for geoprocessing and extraction of different thematic layers applicable in the morphotectonic analysis. The Spatial Analyst Tools (Hydrology) of ArcGIS 10.3.1 were used to generate the flow accumulation, flow direction, drainage network ordering and extraction of catchment boundaries. The DEM and Google Earth imagery were jointly used to delineate catchments based on the surface water divide. Three catchments were identified in the Delhi region named as Delhi east, Delhi central and Delhi west with elevation ranging from 178 to $317 \mathrm{~m}$ (Fig.3). The stream length in each catchment was estimated through ArcGIS software. Survey of India (SoI) toposheets on 1:50,000 scales were also used to manually digitize the higherorder drainage whereas, the lower order drainage was automatically

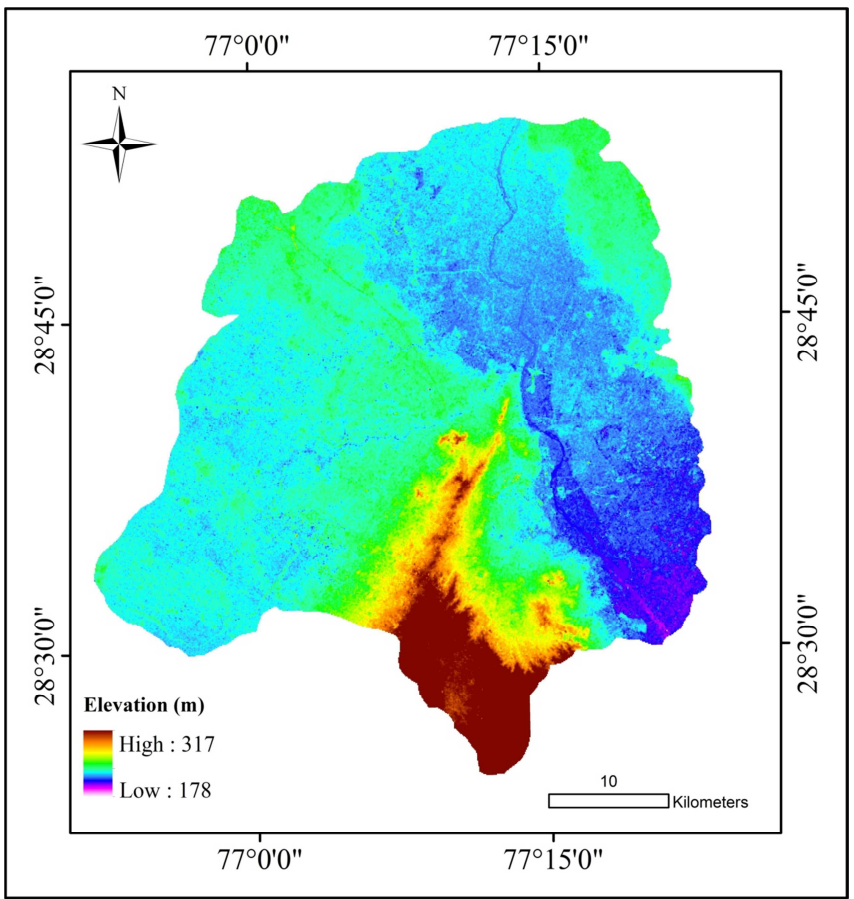

Fig.2. Digital Elevation Model of Delhi region.

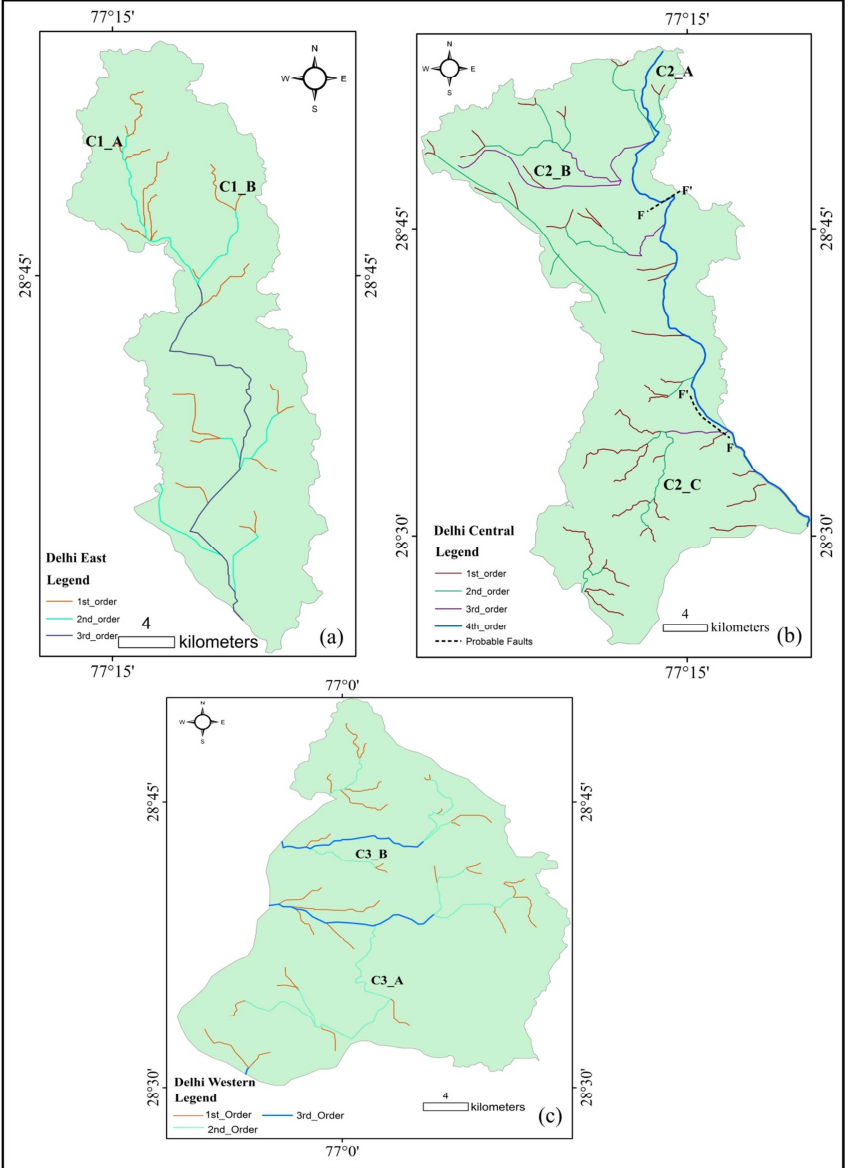

Fig.3. (a) Delhi east (b) Delhi central and (c) Delhi west catchments showing the river channels used for calculation of Stream length gradient Index (SL). The location with high SL values and drop in elevation in the soft sedimentary cover are marked as a fault.

generated by the hydrology tool in ArcGIS software. The stream order was assigned to every stream segment following Strahler's scheme of stream ordering (Strahler, 1952) (Fig.3a-c). The morphotectonic parameters were evaluated using the ArcGIS tools including, Data Management, Editor, Geoprocessing, Spatial Analyst, Hydrology, Raster Calculator, and 3D analyst.

\section{River Longitudinal Profiles}

The curve showing the relationship between height $(\mathrm{H})$ versus distance downstream (L) of a river is known as Longitudinal profiles. The tectonic or rock type perturbations can be easily ascertained through deviation from a concave up shape of stream longitudinal profile (Hack,1973). The longitudinal profiles of 6 river channels of various lengths were prepared (Fig.4) and examined to characterize their shape and the knick zones (high gradient sections) that disrupt river profiles. Due to the presence of heterogeneous geological structure and lithology, no smooth concave-upwards long profile was found in the study area. Out of six, two longitudinal profiles in central and east Delhi are characterized by the presence of knick zones.

\section{Stream Gradient Index (SL)}

Stream gradient index is a practical tool to determine anomalies in the natural concavity at the longitudinal profile i.e. anomalous change in the river gradient. The change in the SL index is a clear indication of sub-surface processes such as active faulting. It is also an indicator sensitive to analyze the reach scale variability of tectonic function, rock resistance, and topography. The stream 
gradient index of the river channel is calculated by (Keller and Pinter, 2002):

$$
S L=(\Delta H / \Delta L) / L
$$

where, $\mathrm{L}$ is the total river length from the midpoint of the chosen to reach whose index is calculated, to the highest point on the channel, $\Delta \mathrm{H} / \Delta \mathrm{L}$ is the channel slope or gradient of the reach in which $\Delta \mathrm{H}$ is a change in elevation for a particular channel of the reach with respect to $\ddot{A} \mathrm{~L}$ which represents the length of the reach.

The SL values obtained are used to assess tectonic activity. The low SL index is an indicator of low seismic activity and with softer and less resistant rock types whereas, the high SL index suggests a high seismic activity; it is generally observed where the stream passes over the hard rocks (Hack, 1973; Keller and Pinter, 2002). The presence of soft rocks with high SL values indicate recent tectonic activity (Keller and Pinter, 2002).

\section{SEISMOLOGICAL ANALYSIS}

\section{Fault Plane Solutions}

The fault plane solutions provide the geometry and mechanism of the fault from the synthesis of seismic waves generated during the earthquake. The fault plane solutions of both NE Delhi earthquakes (12 $2^{\text {th }}$ April 2020 of magnitude $M_{w} 3.5$ and $10^{\text {th }}$ May 2020 of magnitude $M_{w}$ 3.4) were obtained by Pandey et al. (2020) and Bansal et al. (2020) using the ISOLA software package (Table 1). The fault plane solutions of both earthquakes have suggested an NNE-SSW trending causative normal fault with a minor strike-slip component.

\section{Coulomb Failure Static Stress Changes}

It is generally observed that while each earthquake produces a net reduction of regional stress, earthquake events also result in stress increase, thereby influencing the adjacent fault segments (King et al., 1994; Stein, 1999). This may result in a buildup of cumulative stress on the surrounding faults and may trigger subsequent earthquake. The Coulomb stress criterion can be used to estimate the change in stress on the receiver fault plane considering a dislocation model of the source earthquake slip (Beeler et al., 2000).

It is assumed that the fault plane is developed in the rock and the internal frictional coefficient will not change with time. The fault plane will generate shear failure when the shear stress $(\tau)$ reaches the frictional strength $\left(\tau_{f}\right)$. Harris (1998) defined Coulomb $\left(\tau-\tau_{\mathrm{f}}\right)$ failure stress as:

$$
\mathrm{CFS}=\left(\tau-\tau_{\mathrm{f}}\right)=\left(\tau-s-\mu\left(\sigma_{\mathrm{n}}-p\right)\right)
$$

where ' $s$ ' is the cohesion and ' $\mu$ ' is the internal frictional coefficient. ' $\sigma_{\mathrm{n}}$ ' is the normal stress on the fault plane and ' $p$ ' is pore pressure. Then the change in Coulomb failure stress is defined as:

$$
\Delta \mathrm{CFS}=\Delta \tau+\left(\Delta \sigma_{\mathrm{n}}-\Delta \mathrm{p}\right)
$$

where ' $\Delta \tau$ ' is the shear stress in the direction of slip on the receiver fault plane. ' $\Delta \sigma_{\mathrm{n}}$ ' is the change in normal stress (positive for extension), ' $\Delta \mathrm{p}$ ' is the change in pore fluid pressure, and ' $\mu$ ' is the coefficient of friction that have a range from 0.6 to 0.8 for the most intact rocks (Harris, 1998). In the case of a homogeneous and isotropic medium, the equation (2) can be transformed as:

$$
\Delta \mathrm{CFS}=\Delta \tau+\mu^{\prime} \Delta \sigma
$$

where $\mu^{\prime}=\mu(1-\beta)$ is the apparent coefficient of friction, ' $\beta$ ' is the Skempton's coefficient, which describes the change in pore pressure that results from a change in an externally applied stress and often ranges in value from 0.5 to 1.0 (Cocco and Rice, 2002). The theoretical range of the apparent coefficient of friction varies between 0 and 0.8 but is typically found to be around 0.4 (Harris, 1998), which is used in the computation of Coulomb stress changes for minimizing uncertainty (Sumy et al., 2014).

The change in Coulomb stress depends on the surface of interest, regional stress and effective coefficient of friction (King et al., 1994). It also depends on the slip, sense of slip of the fault and geometry of an earthquake. The stress changes on the optimally oriented planes are sensitive to the orientation of the regional stress but insensitive to its magnitude (King et al., 1994).

In the present study, the Coulomb stress changes have been calculated by constraining the geometry and nature of the receiver fault (fault receiving stress from a mainshock) from the focal mechanism solutions of the $12^{\text {th }}$ April 2020 and $10^{\text {th }}$ May 2020 earthquakes.

The elastic half space-based computer program Coulomb 3.1 (Lin and Stein, 2004) is used to estimate static Coulomb stress changes imparted by these earthquakes. Based on the fault plane solutions obtained from waveform inversion, a net slip of $0.0013 \mathrm{~m}$ has been calculated to produce an earthquake with a seismic moment of Mo 2.1e+21 dyne cm, and an earthquake magnitude of $\mathrm{M}_{\mathrm{w}} \sim 3.5$ (Fig. 5).

The fault rupture area is an important and essential parameter for the model application. In the present study due to lack of information on slip distribution, a rectangular fault plane of $3 \times 2 \mathrm{~km}^{2}$ is calculated using the scaling law suggested by Wells and Coppersmith (1994) that was generated using 244 worldwide earthquakes (both interplate and intraplate). Also, we have computed the stress field produced by dislocation sources embedded in a homogeneous elastic half-space considering a Young modulus, shear modulus, Poisson ratio, and coefficient of friction equal to $8 \times 10^{5}$ bars, $3.2 \times 10^{5}$ bars, 0.25 , and 0.4 , respectively. The modelled Coulomb stress changes imparted by the $10^{\text {th }}$ May 2020 earthquake of magnitude $M_{w} 3.4$ have been given in Fig. 6.

\section{RESULTS AND DISCUSSION}

The NE Delhi region experienced earthquakes of magnitude up to $\mathrm{M}_{\mathrm{w}} 3.5$ during April-May 2020. Being a metropolitan city, it is difficult to conduct deep geophysical surveys in the area for delineating the seismic sources. Therefore, the morphometric analysis was carried out using ASTER DEM data of $30 \mathrm{~m}$ resolution and SoI toposheets (1:50,000 scales) of the area to understand the tectonic vulnerability and to identify probable signatures of the causative fault. Three catchments namely, Delhi east, Delhi central, and Delhi west were

\begin{tabular}{|c|c|c|c|c|c|c|c|c|c|c|}
\hline $\begin{array}{l}\text { Origin date and } \\
\text { time }\end{array}$ & $\begin{array}{l}\text { Lat } \\
\left({ }^{\circ} \mathrm{N}\right)\end{array}$ & $\begin{array}{c}\text { Long } \\
\left({ }^{\circ} \mathrm{E}\right)\end{array}$ & $\begin{array}{c}\text { Focal } \\
\text { Depth } \\
(\mathrm{km})\end{array}$ & Str1 & Dip1 & Rak1 & Str2 & Dip2 & Rak2 & $\mathrm{Mw}$ \\
\hline \multicolumn{11}{|l|}{$12 / 04 / 2020^{*}$} \\
\hline $12: 15: 02$ & 28.752 & 77.27 & 16 & $13^{\circ}$ & $55^{\circ}$ & $-135^{\circ}$ & $253^{\circ}$ & $55^{\circ}$ & $-45^{\circ}$ & 3.5 \\
\hline \multicolumn{11}{|l|}{$10 / 05 / 2020^{\#}$} \\
\hline $08: 15: 29$ & 28.797 & 77.28 & 14 & $32^{\circ}$ & $75^{\circ}$ & $-117^{\circ}$ & $275^{\circ}$ & $31^{\circ}$ & $-31^{\circ}$ & 3.4 \\
\hline
\end{tabular}
identified in the Delhi region based on the surface water divide (Fig.3). Due to very low drainage density in the area, two streams from each

Table 1. Source parameters of recent earthquakes of $12^{\text {th }}$ April and $10^{\text {th }}$ May 2020 earthquakes in the NE-Delhi region

* Pandey et al. (2020); \# Bansal et al. (2020) 


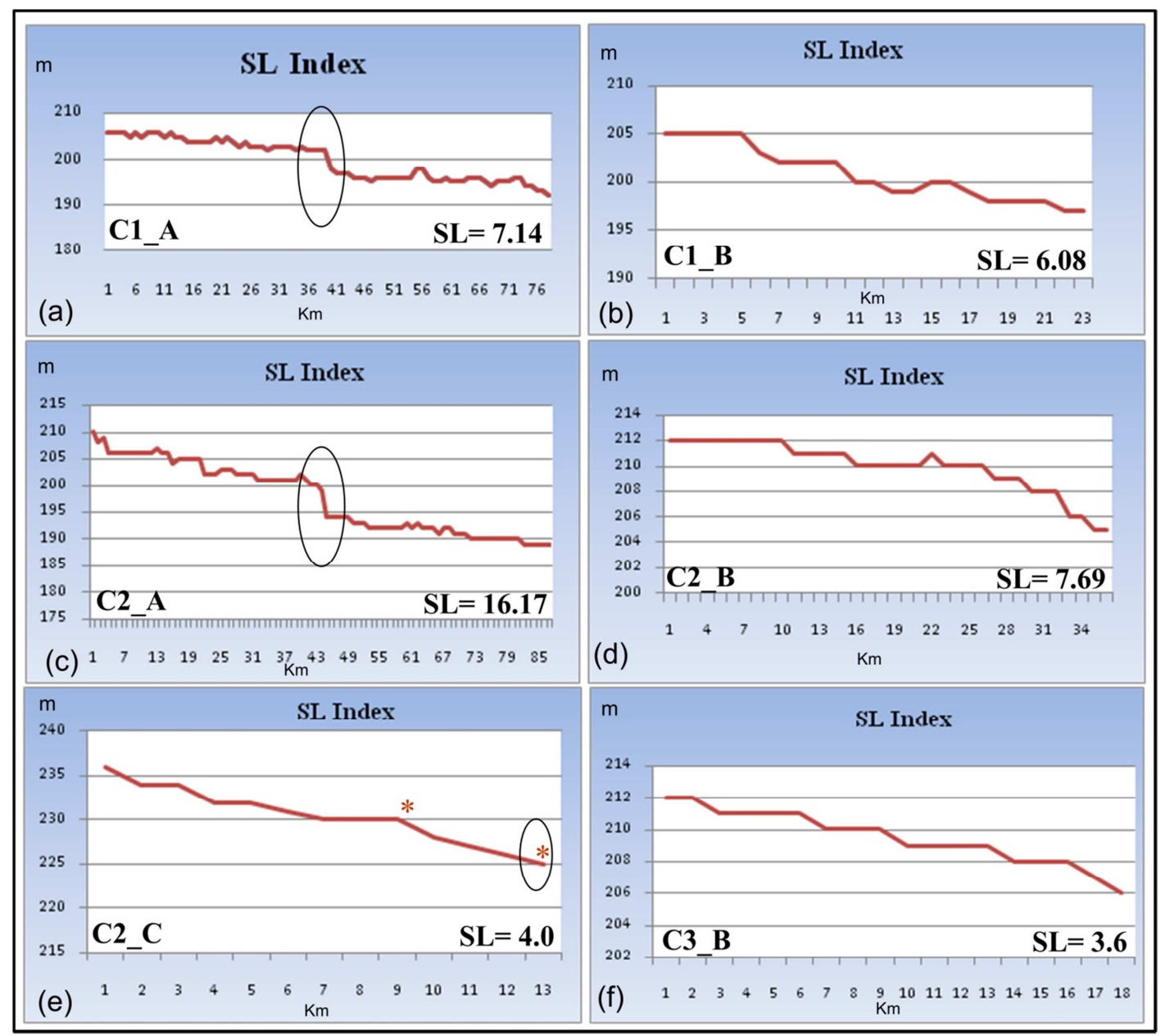

Fig.4. Elevation Profiles of the streams with the stream length gradient index values.

catchment were selected to calculate the SL index. Longitudinal profiles of six selected river channels were examined to characterize their shape and the knick points i.e. high gradient sections that disrupt them.

No smooth concave-upwards long profile has been found in all the three catchment areas due to variation in geological structures and lithology. Out of six longitudinal profiles, two river channels i.e., C2_A and C1_A in Delhi central and Delhi east zones, respectively, are characterized by the presence of knick points. The highest SL index value of 16.17 was calculated for C2_A (Table 2) i.e., the Yamuna river, the longest stream flowing through Delhi central catchment (Fig. 4b). The next higher SL index value of 7.14 was calculated for river channel C1_A (Table 2) flowing parallel to the Yamuna river in Delhi east catchment (Fig.4a). The stream flowing into the Yamuna river in the southern part of the central catchment i.e. C2_C has yielded a value of 4.0 (Table.1), indicating a fall of $5 \mathrm{~m}$ in the elevation of the river profile (Fig. 4e). The Delhi central catchment area with a relatively higher SL index (7.69 - 16.17) is categorized into the class-I group; however, the area with low SL values $(3.60-6.08)$ is grouped into Class-II (Table 2). It is evident from such SL values that the areas falling under Delhi east and Delhi central catchments have been influenced relatively more by the active tectonic deformations, whereas the catchment area in Delhi west has the least impact of tectonic activities (keeping the climatic factors aside).

The highest stream gradient index values on two longitudinal profiles of river channels C2_A, (Fig.4a) in Delhi central and C1_A (Fig.4c) in Delhi east indicate the presence of fault/ lineament running across the river channels. Stream gradient with value 4.0 on the longitudinal profile of the river channel C2_C in the southern part of the Delhi central catchment suggests a fall of $5 \mathrm{~m}$ within a $4 \mathrm{~km}$ region due to the impact of active tectonics (Fig.4e). The cascading profiles of the streams C1_B, C2_B, and C3_B correspond to the man-made structure (Fig.4b,d,f). The SL index suggests that this area might be affected by the local tectonic activity in the recent geological past.

Further, the anomalous values of stream gradient on the longitudinal profiles of both the streams ( 1 1_A and $\left.\mathrm{C} 2 \_\mathrm{A}\right)$ are coinciding with the sharp bends in the Yamuna river (Fig. 7), which act as a strong geomorphic indication of the existence of fault/ lineament. River channel C2_A i.e., the Yamuna river shows a sharp turn and follows about $2 \mathrm{~km}$ NE-SW straight course and again took a sharp U-turn towards SE direction which may indicate the presence of fault crossing the Yamuna river. Two faults/ lineaments have been inferred based on the higher values of stream gradient on longitudinal profiles of two river channels i.e. C2_A and C1_A. The knick zone

Table 2. Stream length Gradient Index (SL) in all three catchment areas

\begin{tabular}{ccc}
\hline Streams/River & SL Index & Class \\
\hline \multicolumn{3}{c}{ Catchment Delhi East } \\
C1_A & 7.14 & I \\
C1_B & 6.08 & II \\
\hline & Catchment Delhi Central \\
C2_A & 16.17 & I \\
C2_B & 7.69 & I \\
C2_C & 4.0 & II \\
\hline & Catchment Delhi West \\
C3_A & 4.47 & II \\
C3_B & 3.6 & II \\
\hline
\end{tabular}




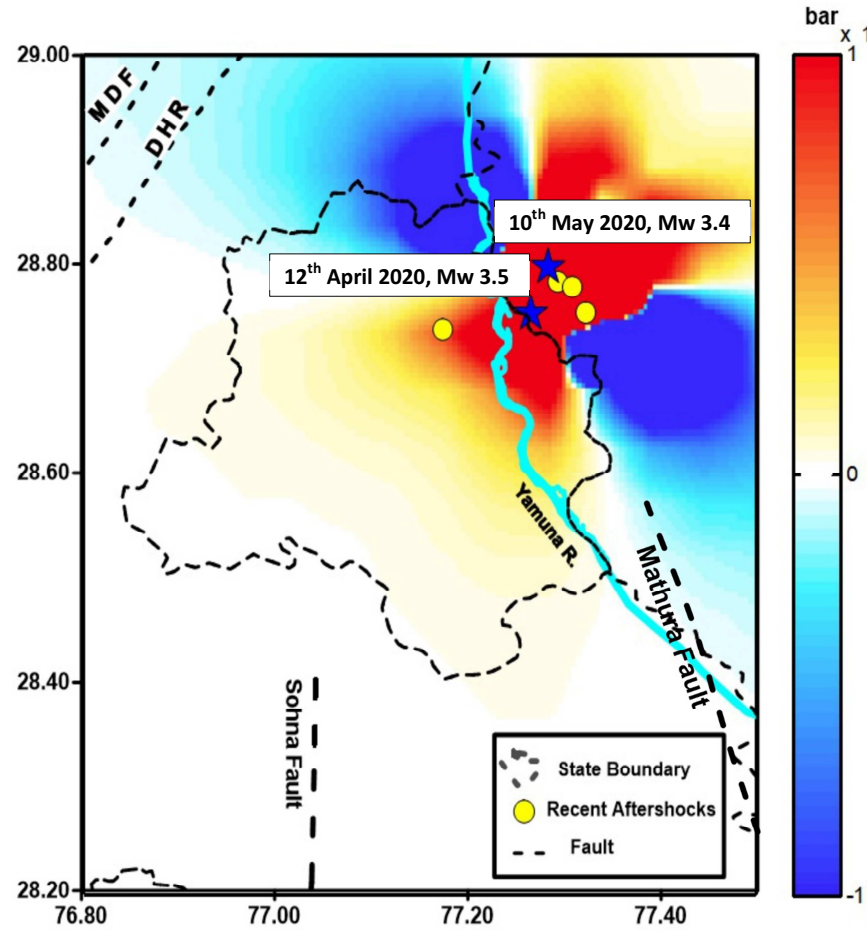

Fig.5. Maps of Coulomb failure stress for $12^{\text {th }}$ April $2020 \mathrm{M}_{\mathrm{w}} 3.5$ Delhi earthquake. The yellow spheres are the aftershocks of the events. The red lobe (positive $\Delta \mathrm{CFS}$ ) and blue (negative $\Delta \mathrm{CFS}$ ).

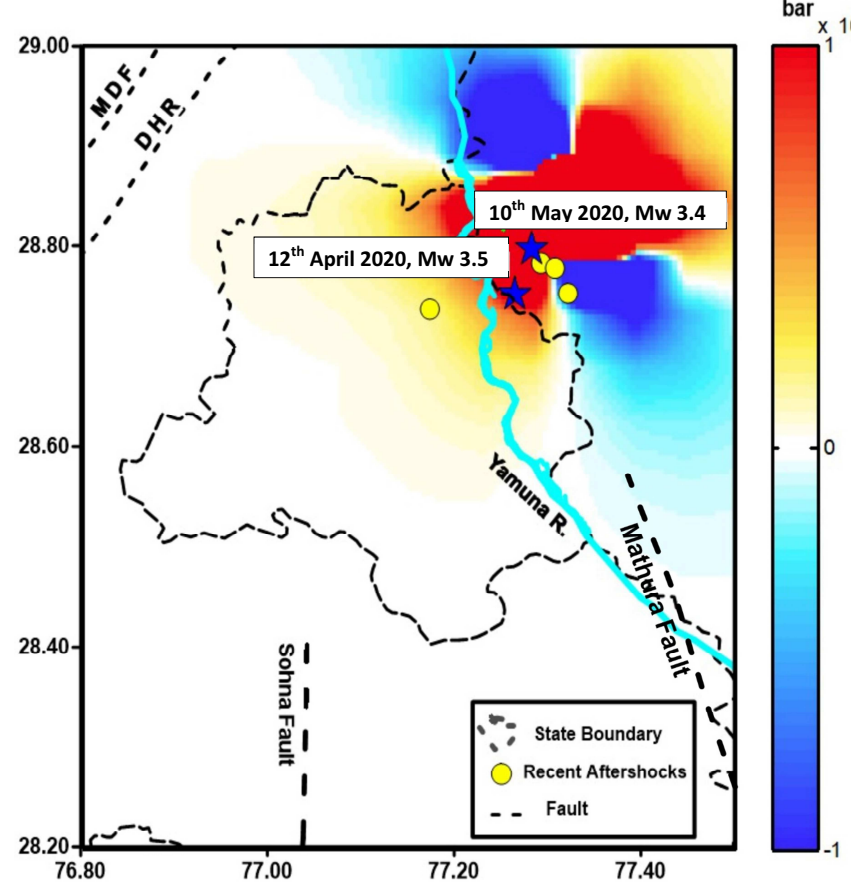

Fig.6. Maps of Coulomb failure stress for $10^{\text {th }}$ May $2020 \mathrm{M}_{\mathrm{w}} 3.4$ Delhi earthquake. The yellow spheres are the aftershocks of the events. The red lobe (positive $\Delta \mathrm{CFS}$ ) and blue (negative $\Delta \mathrm{CFS}$ ).

with the highest stream gradient (16.17) was found close to the epicenters of the recent earthquakes that indicate the presence of a NE-SW trending hidden fault, crossing the Yamuna river (C2_A). It is inferred that this fault as the causative source of the recent earthquakes in the study region.

The NE Delhi earthquakes of $12^{\text {th }}$ April 2020 and $10^{\text {th }}$ May 2020 had occurred at a depth of $\sim 16 \mathrm{~km}$ (Bansal et al., 2020; Pandey et al.,2020). The static Coulomb stress changes at a depth of $16 \mathrm{~km}$ has been calculated assuming the elastic half-space uniform slip model and considering fault plane solutions of the $12^{\text {th }}$ April 2020 and $10^{\text {th }}$

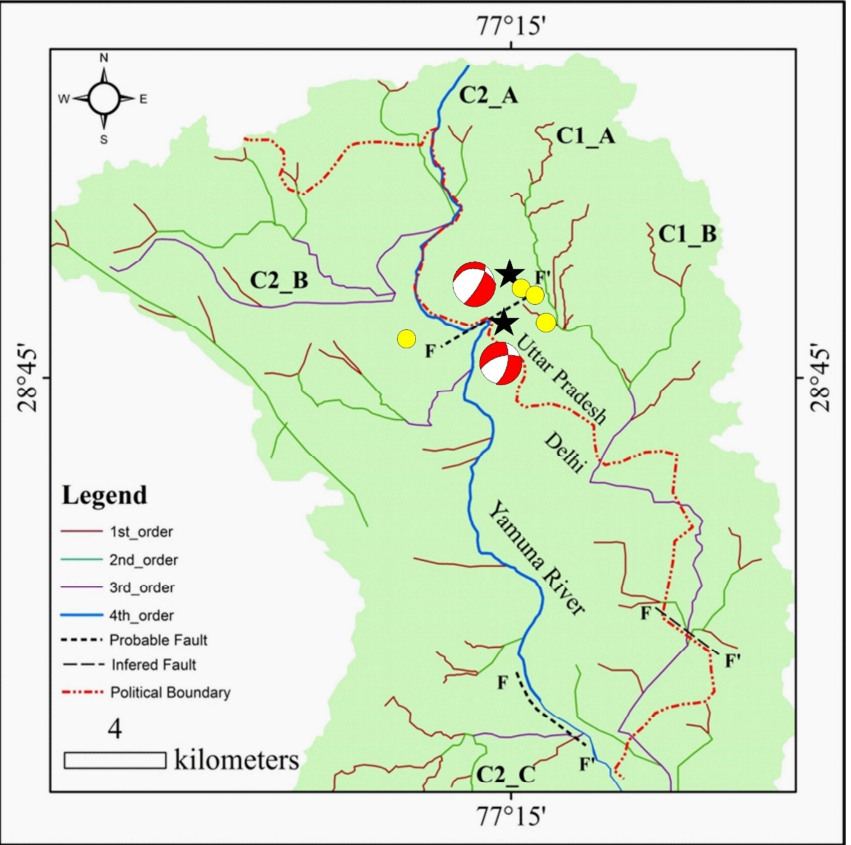

Fig.7. Generalized map of the studied section showing the probable/ inferred faults, drainage system and the streams which were used to calculate Stream length gradient index (C1_A, C1_B, C2_A, C2_B, C2_C). The fault plane solutions (beach balls) of recent NE Delhi earthquakes of $12^{\text {th }}$ April $2020\left(\mathrm{M}_{\mathrm{w}} 3.5\right)$ (upper one) and $10^{\text {th }}$ May $2020\left(M_{w} 3.4\right)$ (lower one) are also shown

May 2020 earthquakes of magnitude $M_{w} 3.5$ and $M_{w} 3.4$, respectively. The static Coulomb stresses are found to be spread out in a butterflyshaped pattern trending NNE-SSW and WNW-ESE beneath the mainshock at a depth of $16 \mathrm{~km}$. Positive changes in $\triangle \mathrm{CFS}$ at the depth of $16 \mathrm{~km}$ indicate an increase in the likelihood of failure due to the mainshock. Numerous studies have suggested a correlation between positive co-seismic stress changes and the location of aftershocks as well as the triggering of moderate to large earthquakes (Harris, 1998). The recent aftershocks superimposed over the Coulomb stress largely fall on a high-stress regime, which indicates an NNE-SSW causative source of the $12^{\text {th }}$ April and $10^{\text {th }}$ May 2020 events (Figs.5 and 6). The fault plane solutions reported by Pandey et al. (2020) and Bansal et al. (2020) for these earthquakes largely show steep dipping normal faulting with strike-slip component (Fig.7). with strike direction of NNE-SSW (Table 1), corroborating well with the findings of the present study.

In summary, morphometric analysis, fault plane solutions, and Coulomb failure stress changes are found to be in close agreement and they establish the presence of a subsurface fault (Fig.7) in the epicentral region of the recent NE Delhi earthquakes. The delineated new hidden fault is named after the locality as Khanpur-Japti fault.

\section{CONCLUSION}

Six earthquakes of magnitude up to $\mathrm{M}_{\mathrm{w}} 3.5$ have occurred recently (April-May 2020) in the NE Delhi region. The epicentral area is thickly populated and is not readily amenable to deep geophysical surveys. Therefore, an attempt has been made to constrain the causative fault of the recent seismicity using morphotectonic analysis, Coulomb's failure stress changes, and fault plane solutions. The morphotectonic indices (SL index) and the elevation profile of Yamuna river suggest the likely presence of a NE-SW trending active tectonic structure in the epicentral region, which is interpreted to be a fault across the Yamuna river. The static failure stress change estimates in the region suggest a likelihood of failure at a depth of $\sim 16 \mathrm{~km}$ along an NNE-SSW trending causative fault. The joint, seismological and 
morphometric, analyses suggest the presence of an NNE-SSW-oriented fault at the same location. The aftershocks also followed the highstress regime calculated from the Coulomb failure stress change estimates, confirming it as the causative fault of the recent seismicity in the Delhi region. The inferred new hidden fault is named as KhanpurJapti fault after the name of a village in the area.

Acknowledgments: We are thankful to the National Centre for Seismology, Ministry of Earth Sciences for permitting us to publish the research work. Comments and suggestions offered by AP Pandey and the reviewer helped in improving the MS.

\section{References}

Bansal, B.K., Mohan, K., Verma, M. and Sutar, A.K. (2020) A Holistic Seismotectonic Model of Delhi Region, Scientific Reports (communicated)

Beeler, N.M., R.W. Simpson, S.H. Hickman, and D.A. Lockner (2000) Pore fluid pressure, apparent friction and Coulomb failure, Jour. Geophys. Res., v.105(B11), pp.25,533-25,542.

Clark, M.K., Schoenbohm, L.M., Royden, L.H., Whipple, K.X., Burchfiel, B.C., Zhang, X., Tang, W., Wang, E., and Chen, L. (2004) Surface uplift, tectonics, and erosion of eastern Tibet from large-scale drainage patterns. Tectonics, v.23(1), pp.TC1006.

Cocco, M. and Rice, J.R. (2002) Pore pressure and poro-elasticity effects in Coulomb stress analysis of earthquake interactions. Jour. Geophys. Res., v.107(B2), pp.1-17.

Das, S. and Scholz, C. (1981) Off-fault aftershock clusters caused by shear stress increase? Bull. Seismol. Soc. Amer., v.71, pp.1669-1675.

GSI (2000) Seismotectonic atlas of India and its environs. Published by Geological Survey of India, Calcutta.

Hack, J.T. (1973) Stream-profile analysis and stream-gradient index. Jour. Res. USGS, v.1(4), pp.421-429.

Harris, R.A. (1998) Introduction to special section: stress triggers, stress shadows, and implications for seismic hazard. Jour. Geophys. Res., v.103(10), pp.24347-24358.

Howard, A.D. (1967) Drainage Analysis in Geologic Interpretation: A Summation. AAPG Bull., v.51, pp.2246-2259.

Kachroo, K. and Bagchi, J. (1999) Report on the thematic mapping of the rocks of Delhi Supergroup in the National Capital Region Delhi. Unpub. Geol. Surv. India Report (FS: 1998-99).

Keller, E.A. and Pinter, N. (2002) Active Tectonics: Earthquakes, Uplift, and Landscape, 2nd ed. Prentice-Hall, Upper Saddle River, New Jersey, p.362.

King, G.C.P., Stein, R.S. and Lin, J. (1994) Static stress changes and the triggering of earthquakes. Bull. Seismol. Soc. Amer., v.84, pp.935-953.

Lin,J., and Stein, R.S. (2004) Stress triggering in thrust and subduction earthquakes, and stress interaction between the southern San Andreas and nearby thrust and strike slip faults. Jour. Geophys. Res., v.109, pp.B02303, DOI:10.1029/2003JB002607.

Pandey, A.P., Suresh, G., Singh, A.P., Sutar, A.K. and Bansal, B.K. (2020) A widely felt Tremor (ML 3.5) of 12 April 2020 in and around NCT Delhi in the backdrop of prevailing COVID-19 pandemic lockdown: analysis and observations, Geomatics, Natural Hazards and Risk, v.11(1), pp.16381652, DOI: 10.1080/19475705.2020.1810785.

Pirasteh, S., Ali, S.A. and Hussaini, S. (2007) Morphometric and structural analysis in Zagros Mountains, Southwest Iran: An application of geoinformation technology. Jour. Geomatics, v.1(2), pp.39-44.

Strahler, A.N. (1952) Hypsometric (area-altitude) analysis of erosional topology, Geol. Soc. Amer. Bull., v.63(11), pp.1117-1142.

Stein, R.S. (1999) The role of stress transfer in earthquake occurrence. Nature, v.402, pp.605-609.

Sumy, D.F., Cochran, E.S., Keranen, K.M., Wei, M. and Abers, G.A. (2014) Observations of static Coulomb stress triggering of the November 2011 M5.7 Oklahoma earthquake sequence. Jour. Geophys. Res., v.119, pp.1904-1923.

Well, D.L. and Coppersmith, K.J. (1994) New empirical relationship among magnitude, rupture, length, rupture area, and surface displacement. Bull. Seismol. Soc. Amer., v.84, pp.974-1002.

Yamashina, K. (1978) Induced earthquakes in the Izu Peninsula by the IzuHanto-Oki earthquake of 1974, Japan, Tectonophysics, v.51, pp.139154 .

(Received: 14 October 2020; Revised form accepted: 2 February 2021) 